\title{
Evaluation of Endogenous Phytocomponents and Amino Acids Associated with Direct Somatic Embryogenesis of Coffee (Coffea arabica L.)
}

\author{
Mayoli, R.N. ${ }^{1,2}$, Isutsa, D.K. ${ }^{2,3}$, Nyende, A.B. ${ }^{4}$ and Mweu, C.M. ${ }^{4}$ \\ ${ }^{1}$ KALRO-Coffee Research Institute, P. O. Box 4-00232, Ruiru, Kenya \\ Email: rosemayoli@yahoo.com \\ ${ }^{2}$ Chuka University, P. O. Box 109-60400, Chuka, Kenya, ${ }^{3}$ Egerton University, P. O. Box 536-20115, Egerton, \\ Kenya \\ Email: dorcaski@yahoo.com \\ ${ }^{4}$ Jomo Kenyatta University of Agriculture and Technology, P. O. Box 62000-00200, Nairobi, Kenya
}

\begin{abstract}
Coffee is one of the most important crops cultivated in the world for use in beverages and confectionaries. Embryogenesis is a complex process that begins with a single cell and ends with the formation of mature embryos. Somatic embryo development involves accumulation of complex metabolites and storage reserves. This present experiment identified and quantified endogenous phytocomponents and amino acids present during somatic embryogenesis of 'Ruiru $11^{\prime}$. Laboratory experiments for this study were set up in the Coffee Research Institute, Kenya at Ruiru. Third leaf pair explants were excised from 8-month-old greenhouse-grown mother plants sterilized and cultured in half strength Murashige and Skoog basal salts augmented with Thidiazuron. Once embryos had developed, the cultures were analysed for phytocomponents using GCMS and HPLC. The results showed that palmitoleic and stearic acids were highest $(23.3 \mu \mathrm{g} / \mathrm{g}$ and $69.9 \mu \mathrm{g} / \mathrm{g}$ respectively) in brown embryogenic cultures. Cis 7,8 epoxy-2-methyl octadecane was highest $(253 \mu \mathrm{g} / \mathrm{g})$ in green embryogenic cultures. (Z)-3-Tetradecene was highest $(25 \mu \mathrm{g} / \mathrm{g})$ in brown non-embryogenic cultures. Z, Z-3,13Octadecedien-1-ol and (Z)-7-Hexadecenal were highest $(32.1 \mu \mathrm{g} / \mathrm{g}$ and $70.2 \mu \mathrm{g} / \mathrm{g}$ respectively) in green embryogenic cultures. Alanine content was highest $(4.4 \mu \mathrm{g} / \mathrm{g})$ in embryos of brown cultures. Amino acids, fatty acids and their derivatives are potential biomarkers for embryogenesis. Other phytocomponents should be identified and their role in coffee somatic embryogenesis determined. Further studies regarding the status of the phytocomponents identified in the present study, especially in particular stages of embryo development are needed to propose treatments to improve coffee somatic embryo development.
\end{abstract}

Keywords: Amino acids, Biomarkers, Fatty acids, Somatic embryos

Date of Publication: 30.5 .2018

DOI: 10.24297/jaa.v8i1.7377

ISSN: 2349-0837

Volume: 8 Issue: 01

Journal: Journal of Advances in Agriculture

Website: https://cirworld.com

This work is licensed under a Creative Commons Attribution 4.0 International License.

\section{Academic Discipline and Subdiscipline}

Horticulture

\section{Subject Classification}

Plant Biotechnology

Type

Tissue culture 


\title{
Evaluation of Endogenous Phytocomponents and Amino Acids Associated with Direct Somatic Embryogenesis of Coffee (Coffea arabica L.)
}

\author{
Mayoli, R.N. ${ }^{1,2}$, Isutsa, D.K. ${ }^{2,3}$, Nyende, A.B. ${ }^{4}$ and Mweu, C.M. ${ }^{4}$ \\ ${ }^{1}$ KALRO-Coffee Research Institute, P. O. Box 4-00232, Ruiru, Kenya \\ Email: rosemayoli@yahoo.com \\ ${ }^{2}$ Chuka University, P. O. Box 109-60400, Chuka, Kenya, ${ }^{3}$ Egerton University, P. O. Box 536-20115, Egerton, \\ Kenya \\ Email: dorcaski@yahoo.com \\ ${ }^{4}$ Jomo Kenyatta University of Agriculture and Technology, P. O. Box 62000-00200, Nairobi, Kenya
}

\begin{abstract}
Coffee is one of the most important crops cultivated in the world for use in beverages and confectionaries. Embryogenesis is a complex process that begins with a single cell and ends with the formation of mature embryos. Somatic embryo development involves accumulation of complex metabolites and storage reserves. This present experiment identified and quantified endogenous phytocomponents and amino acids present during somatic embryogenesis of 'Ruiru $11^{\prime}$ '. Laboratory experiments for this study were set up in the Coffee Research Institute, Kenya at Ruiru. Third leaf pair explants were excised from 8-month-old greenhouse-grown mother plants sterilized and cultured in half strength Murashige and Skoog basal salts augmented with Thidiazuron. Once embryos had developed, the cultures were analysed for phytocomponents using GCMS and HPLC. The results showed that palmitoleic and stearic acids were highest $(23.3 \mu \mathrm{g} / \mathrm{g}$ and $69.9 \mu \mathrm{g} / \mathrm{g}$ respectively) in brown embryogenic cultures. Cis 7,8 epoxy-2-methyl octadecane was highest $(253 \mu \mathrm{g} / \mathrm{g})$ in green embryogenic cultures. (Z)-3-Tetradecene was highest $(25 \mu \mathrm{g} / \mathrm{g})$ in brown non-embryogenic cultures. $Z$, Z-3,13-Octadecedien-1-ol and (Z)-7-Hexadecenal were highest $(32.1 \mu \mathrm{g} / \mathrm{g}$ and $70.2 \mu \mathrm{g} / \mathrm{g}$ respectively) in green embryogenic cultures. Alanine content was highest $(4.4 \mu \mathrm{g} / \mathrm{g})$ in embryos of brown cultures. Amino acids, fatty acids and their derivatives are potential biomarkers for embryogenesis. Other phytocomponents should be identified and their role in coffee somatic embryogenesis determined. Further studies regarding the status of the phytocomponents identified in the present study, especially in particular stages of embryo development are needed to propose treatments to improve coffee somatic embryo development.
\end{abstract}

Keywords: Amino acids, Biomarkers, Fatty acids, Somatic embryos

Date of Publication: 30.5.2018

DOI: $10.24297 /$ jaa.v\%vi\%i.7377

ISSN: 2349-0837

Volume: 8 Issue: 02

Journal: Journal of Advances in Agriculture

Website: https://cirworld.com

This work is licensed under a Creative Commons Attribution 4.0 International License.

\section{Academic Discipline and Subdiscipline}

Horticulture

\section{Subject Classification}

Plant Biotechnology

Type

Tissue culture 


\section{INTRODUCTION}

Embryogenesis is a spatio-temporally organized developmental process central to the life cycles of diverse plant species (Navarro et al., 2017). The most important stage is the maturation phase where a switch from a regional and cell-specification programme to a storage accumulation programme occurs (Yadegari and Goldenburg, 1997). The switch prepares embryos for post-embryonic development involving synthesis and accumulation of nutrient reserves, suppression of precocious germination, acquisition of desiccation tolerance and, in some species, induction of dormancy (Koorneef and Karseen, 1994). The histo-differentiation of somatic embryos is normally associated with changes in synthesis and mobilization of proteins, carbohydrates, and lipids, whose levels change along the developmental stages of cultures (Lulsdorf et al., 1992). Coffee is rich in bioactive compounds or phytocomponents (Dong et al, 2015). Fatty acids are molecules attached to other compounds such as sugars, glycerol or phosphates to form lipids (Karimi et al., 2015) and are associated with many biological activities. Hydrocarbons, especially the $\mathrm{n}$-alkanes are highly hydrophobic aliphatic molecules and important components of the cuticle where they assist in maintaining plant water balance (Cunha and Fernandes-Ferreira, 2001). Aldehydes arise from degradation of polyunsaturated fatty acids by autoxidation or action of enzymes such as lipoxygenases (Takahashi et al., 2002). Hydrocarbons, aldehydes and alcohols are products of the enzymatic breakdown of unsaturated fatty acids (El Hadi et al., 2013). This paper reports results of phytocomponents and amino acids identified and quantified during development of coffee somatic embryos in vitro.

\section{MATERIALS AND METHODS}

\subsection{Preliminary preparations}

The present experiment was conducted in the laboratories and greenhouses of the Coffee Research Institute at Ruiru in Kenya. The site is situated $1.05^{\circ} \mathrm{S}$ and $36.45^{\circ} \mathrm{E}$ at an elevation of $1608 \mathrm{~m}$ above the sea level and has humic nitosol soils (Jaetzold et al., 2007). The Coffea arabica cultivar Ruiru 11 planted at this site was used in the experiment. The plants were moved from the fields to laboratories for experimentation and then to greenhouses.

The mother plants for this experiment were obtained from germination of Ruiru 11 seeds. The resulting seedlings were transplanted to polybags filled with top soil: sand: manure $(3: 2: 1 \mathrm{v} / \mathrm{v})$ and maintained in the greenhouse for about 8 months. Third leaf pair explants were excised from the greenhouse-grown mother plants between March and April, 2014. The leaves were washed thoroughly under running tap water followed by water containing Teepol detergent and finally sterile distilled water.

The subsequent sterilization steps were done in a laminar flow cabinet. The leaves were dipped quickly for 30 seconds in 70\% alcohol and rinsed 2-3 times in sterile distilled water. The leaves were sterilized further using $25 \%$ sodium hypochlorite for 25 minutes followed by rinsing thoroughly four times in sterile distilled water. The culture medium contained half-strength Murashige and Skoog (1962) inorganic basal salts, supplemented with $0.2 \mathrm{~g} / \mathrm{L}$ thiamine, $0.1 \mathrm{~g} / \mathrm{L}$ nicotinic acid, $0.1 \mathrm{~g} / \mathrm{L}$ pyridoxine, $30 \mathrm{~g} / \mathrm{L}$ sucrose, $100 \mathrm{mg} / \mathrm{L}$ myo-inositol, $100 \mathrm{mg} / \mathrm{L}$ cysteine, $3 \mathrm{~g} / \mathrm{L}$ gelrite, and $1 \mathrm{ml} / \mathrm{L}$ Thidiazuron. The $\mathrm{pH}$ of the medium was adjusted to 5.7 using $1 \mathrm{M} \mathrm{NaOH}$ or 1 $\mathrm{M} \mathrm{HCl}$ and $3 \mathrm{~g} / \mathrm{L}$ gelrite added before autoclaving for 15 minutes at $121^{\circ} \mathrm{C}$ and $100 \mathrm{kPa}$. Culture medium $(25 \mathrm{ml})$ was poured into Magenta boxes (Sigma Chemical Co.) and 5 leaf discs $\left(1 \mathrm{~cm}^{2}\right)$ cultured in each vessel maintained in darkness, $25 \pm 2^{\circ} \mathrm{C}$ and $70 \%$ relative humidity for about 8 months. A total of 627 culture vessels were prepared, of which 183 vessels (29\%) were discarded because of fungal contamination.

\subsection{Treatments}

Treatments for this experiment were selected from the remaining 444 clean culture vessels. Culture vessels with green and brown leaf discs with and without embryos as shown in Plate 1 were used to characterise amino acids and phytocomponents in the leaf discs, embryos and medium. Fresh culture medium and leaf explants excised from greenhouse-grown mother plants were used as controls. The experimental layout was completely randomized design, with three replications and six culture vessels per treatment. The experiment was repeated once. 

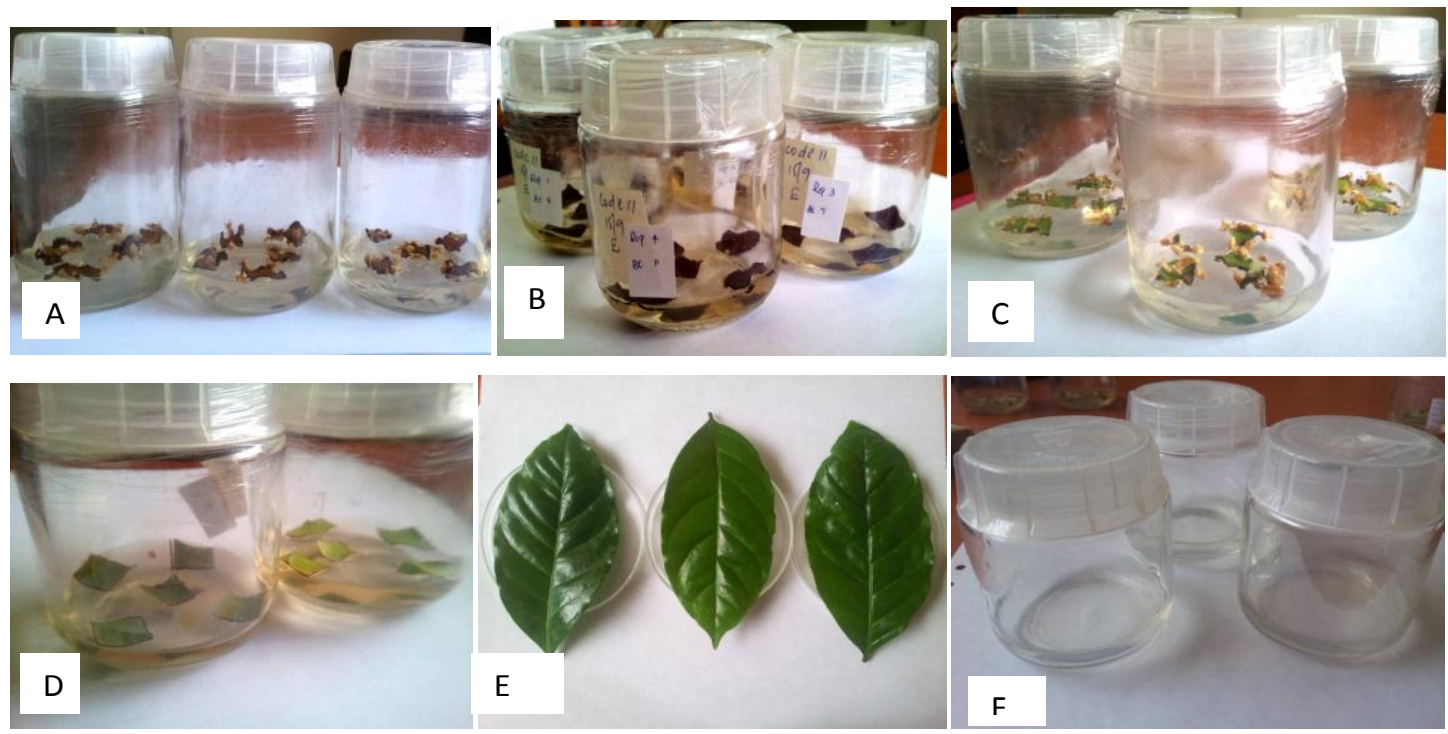

Plate 1: Treatments set up. A: Brown leaf discs with embryos. B: brown leaf discs without embryos. C: green leaf discs with embryos. D: Green leaf discs without embryos, E: Fresh leaves (control). F: Fresh media (control)

\subsection{Extraction, identification and quantification of phytocomponents}

Phytocomponents were extracted as described by Shettima et al. (2013) with modifications. Fifty (50) ml methanol was added to the culture vessels containing green and brown leaf discs, with and without embryos and immediately deep-frozen overnight at $-20^{\circ} \mathrm{C}$. The polarity of the samples was increased before partitioning against ethyl acetate, and about $1 \mathrm{ml}$ of distilled water which had been adjusted to $\mathrm{pH} 8$ added. The $\mathrm{pH}$ of the samples was further adjusted to over 9 using $1 \mathrm{M} \mathrm{KOH}$ to keep the phytocomponents ionized and then partitioned against 100\% ethyl acetate. The aqueous and organic phases were separated using a funnel and the lower aqueous phase was transferred to a new $10 \mathrm{ml}$ tube. The $\mathrm{pH}$ of the solution was lowered to below 3 using concentrated acetic acid to conserve the phytocomponents in protonated form. The acidic sample was partitioned against $100 \%$ ethyl acetate and dried by passing through anhydrous sodium sulphate. The sample were spiked with 50 ppm internal standard (Benzophenone) and analyzed with Gas Chromatograph-Mass Spectrophotometer (GCMS).

\subsection{Extraction, identification and quantification of amino acids}

Amino acids were extracted as described by AOAC (1997). Leaf disc, embryo and medium samples from culture vessels with green and brown leaf discs with and without embryos were weighed into screw-cap Pyrex borosilicate tubes. About $2 \mathrm{ml}$ of performic acid was added to each sample followed by incubation at $0^{\circ} \mathrm{C}$ for 16 hours. About $0.84 \mathrm{~g}$ sodium metabisulfite and $3 \mathrm{~mL} 6 \mathrm{~N}$ hydrochloric acid were added to each mixture. The tubes were thoroughly flushed with nitrogen, quickly capped, and placed in an oven at $110^{\circ} \mathrm{C}$ for 24 hours. Approximately $250 \mu \mathrm{l}$ of the hydrolysed extracts was evaporated under a stream of nitrogen. The residue extract was re-dissolved in $1 \mathrm{ml} 0.1 \mathrm{M}$ borate buffer and filtered through $0.2 \mu \mathrm{M}$ syringe filters and analysed with High Performance Liquid Chromatography (HPLC).

\subsection{Data collection on phytocomponents}

Identification relied on matching the mass spectrometric fragmentation patterns corresponding to the various peaks in the samples total ion chromatogram with those present in the National Institute of Science and Technology mass spectral database. Integration was done automatically for the individual peaks. Each sample was spiked with 50 ppm internal standard (Benzophenone) and injected into GC-MS (Model QP2010 SE, Shimadzu) fitted with DB 5 column. The detector MS and Helium was used as the carrier gas at a flow rate of 1 $\mathrm{ml} / \mathrm{min}$. The phytocomponents were estimated using the following equation: 
Concentration of analyte $\left(C_{1}\right)=$ Peak area of analyte/peak area of internal standard $x$ concentration of internal standard.

Content $(\mu \mathrm{g} / \mathrm{g})$ of the analyte $=\left[C_{1} \times \mathrm{V}\right] / \mathrm{W}$, Where $C_{1}=$ the concentration $(\mathrm{ppm})$ of the analyte in the test solution, $V=$ the volume $(\mathrm{mL})$ of the test solution, and $\mathrm{W}=$ the weight $(\mathrm{g})$ of the sample used for preparation of the test solution.

\subsection{Data collection on amino acids}

Amino acids were analyzed by injecting about $50 \mu \mathrm{l}$ of the eluate sample into Knauer HPLC system equipped with a super Co Discovery C-18 column at a flow rate of $1 \mathrm{ml} /$ minute under ambient temperature. A Knauer fluorescent detector was used at excitation wavelength of $350 \mathrm{~nm}$ and emission wavelength of $450 \mathrm{~nm}$. Two mobile phases were used: Mobile Phase $\mathrm{A}$ was $0.01 \mathrm{M} \mathrm{Na}_{2} \mathrm{HPO}_{4}$ at $\mathrm{pH} 8.2$ prepared by dissolving $1.42 \mathrm{~g}$ disodium phosphate heptahydrate $\left(\mathrm{Na}_{2} \mathrm{HPO}_{4}\right)$ and $3.81 \mathrm{~g}$ sodium borate $\left(\mathrm{Na}_{2} \mathrm{~B}_{4} \mathrm{O}_{7} .10 \mathrm{H}_{2} \mathrm{O}\right)$ in $950 \mathrm{ml}$ milliQ reagent grade water then adding $32 \mathrm{mg}$ sodium azide $\left(\mathrm{NaN}_{3}\right)$. The $\mathrm{pH}$ was adjusted to 8.2 using $5 \mathrm{~N} \mathrm{HCl}$ and filled up to 1 litre volume. Mobile Phase B was 45 methanol: 45 acetonitrile: 10 water.

Amino acids were identified by comparing the retention time of multi-amino acid standard mixture (99\%) (Cat No. AAS18, Sigma-Aldrich) with the sample peaks. The concentration was calculated from peak areas using calibration equations, namely:

Concentration of analyte $(\mathrm{Cl})=$ Peak area of analyte/slope of the standards' calibration curve. Content $(\mathrm{mg} / \mathrm{g})$ of the analyte $=[\mathrm{C} 1 \times \mathrm{V} \times \mathrm{M} \times 100] / \mathrm{W} \times 1000$, Where $\mathrm{C} 1=$ the concentration $(\mathrm{pmol} / \mathrm{ml})$ of the analyte in the test solution, $\mathrm{V}=$ the volume (dilution factor), of the test solution, and $\mathrm{W}=$ the weight $(\mathrm{mg})$ of the sample used for preparation of the test solution.

\subsection{Data analysis}

The SAS 9.2 computer software was used to analyze data by subjecting to analysis of variance using the General Linear Model for a completely randomized design (CRD). The linear model fitted to the CRD data was: $Y_{i j}=\mu+$ $T_{i}+\varepsilon_{i j}$, Where: $\mu$ is grand mean, $T_{i}$ is ith concentration of the endogenous factor; $i=1,2,3 \ldots 10,11,12 ; j=1,2$, 3 ; and $\varepsilon_{i j}$ is random error component, normally and independently distributed about zero mean with a common variance $\sigma^{2}$. Differences between treatment means were separated using the LSD test at $P=0.05$.

\section{RESULTS}

\subsection{Evaluation of phytocomponents}

Several phytocomponents were identified and classified as fatty acids, alcohols, aldehydes and hydrocarbons (Tables 1 to 5 ).

\subsubsection{Fatty acids}

Significant $(P<0.05)$ differences in the various fatty acids identified resulted for all the treatments (Table 1). Oleic and elaicid acid unsaturated fatty acids were present in most of the treatments. The fresh leaves contained the highest $(P<0.05) 133.98 \mu \mathrm{g} / \mathrm{g}$ oleic acid, followed by $35.05 \mu \mathrm{g} / \mathrm{g}$ pentadecanoic acid, $195.91 \mu \mathrm{g} / \mathrm{g}$ palmitic acid, $138.1 \mu \mathrm{g} / \mathrm{g}$ margaric acid, and $75.98 \mu \mathrm{g} / \mathrm{g}$ nonadecyclic acid. Brown leaf discs with embryos had the highest $(P>0.05) 23.27 \mu \mathrm{g} / \mathrm{g}$ palmitoleic acid and $69.92 \mu \mathrm{g} / \mathrm{g}$ stearic acid, whereas brown leaf discs without embryos had the highest $7.04 \mu \mathrm{g} / \mathrm{g}$ lauric acid and $38.62 \mu \mathrm{g} / \mathrm{g}$ caprylic acid.

\subsubsection{Hydrocarbons}

There were significant $(P<0.05)$ differences in endogenous hydrocarbons found in the various treatments (Table 2). Green cultures with embryos had $46 \mu \mathrm{g} / \mathrm{g}$-[(hexadecyloxy)methyl]-Oxirane, followed by $8 \mu \mathrm{g} / \mathrm{g} \mathrm{1,1,3,3-}$ tetraethyl-2,1,3-Oxadisilacyclopentane, $2 \mu \mathrm{g} / \mathrm{g} \quad$-2-Trifluoroacetoxydodecane, $2 \mathrm{\mu g} / \mathrm{g} \quad 2$-Cyclopropyl carbonyloxytetradecane, $253 \mu \mathrm{g} / \mathrm{g}$ Cis 7,8 epoxy-2-methyl octadecane, $13 \mu \mathrm{g} / \mathrm{g}$ 1-sulphonyl chloride Octadecane and $43 \mu \mathrm{g} / \mathrm{g}$ 11,20-didecyl-Triacontane content. Brown cultures with embryo had $30 \mu \mathrm{g} / \mathrm{g}$ Heptadecane content. Green cultures without embryos had the highest $39 \mathrm{\mu g} / \mathrm{g}$ hexadecyl-Oxirane followed by $4 \mathrm{\mu g} / \mathrm{g}$ 1-chloro-7-Heptadecene content. Brown cultures without embryos had the highest $21 \mu \mathrm{g} / \mathrm{g}$ 1-iodoTridecane, $9 \mu \mathrm{g} / \mathrm{g}$ 1,1-bis(dodecyloxy)-Hexadecane, $8 \mu \mathrm{g} / \mathrm{g}$ 6-methyl-Octadecane, $9 \mu \mathrm{g} / \mathrm{g}$ Hexatriacontane, 25 $\mu \mathrm{g} / \mathrm{g}$ (Z)-3-Tetradecene, $12 \mu \mathrm{g} / \mathrm{g}$ (E)-9-Octadecene and $5 \mu \mathrm{g} / \mathrm{g}$ 1-Docosene content. The $21 \mu \mathrm{g} / \mathrm{g} \mathrm{N}$ - 
Octylidencyclohexane content was not significantly $(P>0.05)$ different in green and brown cultures, although this content was different from the other treatments. 
Table 1: Fatty acids content $(\mu \mathrm{g} / \mathrm{g})$ during development of coffee somatic embryos

\begin{tabular}{lllllllll}
\hline Treatments & $\begin{array}{l}\text { Palmitoleic } \\
\text { acid C16:1 }\end{array}$ & $\begin{array}{l}\text { Elaidic Acid } \\
\text { Trans C18:1 }\end{array}$ & $\begin{array}{l}\text { Oleic acid } \\
\text { C18:1 }\end{array}$ & $\begin{array}{l}\text { Lauric } \\
\text { acid } \\
\text { C12:0 }\end{array}$ & $\begin{array}{l}\text { Caprylic } \\
\text { acid } \\
\text { C8:0 }\end{array}$ & $\begin{array}{l}\text { Pentadecanoic } \\
\text { Acid } \\
\text { C15:0 }\end{array}$ & $\begin{array}{l}\text { Palmitic } \\
\text { acid } \\
\text { C16:0 }\end{array}$ & $\begin{array}{l}\text { Margaric } \\
\text { acid } \\
\text { C17:0 }\end{array}$ \\
\hline GE & $19.0^{\mathrm{b}}$ & $1.99^{\mathrm{d}}$ & $42.84^{\mathrm{b}}$ & $0^{\mathrm{c}}$ & $0^{\mathrm{b}}$ & $0^{\mathrm{b}}$ & $19.95^{\mathrm{b}}$ & $43.08^{\mathrm{b}}$ \\
$\mathrm{BE}$ & $23.3^{\mathrm{a}}$ & $1.13^{\mathrm{e}}$ & $32.32^{\mathrm{c}}$ & $0^{\mathrm{c}}$ & $0^{\mathrm{b}}$ & $0^{\mathrm{b}}$ & $17.9^{\mathrm{c}}$ & $32.17^{\mathrm{bc}}$ \\
$\mathrm{GW}$ & $0.0^{\mathrm{d}}$ & $15.01^{\mathrm{a}}$ & $18.68^{\mathrm{d}}$ & $3.67^{\mathrm{b}}$ & $0^{\mathrm{b}}$ & $0^{\mathrm{b}}$ & $21.48^{\mathrm{b}}$ & $12.12^{\mathrm{d}}$ \\
$\mathrm{BW}$ & $0.0^{\mathrm{d}}$ & $11.12^{\mathrm{b}}$ & $16.51^{\mathrm{d}}$ & $7.04^{\mathrm{a}}$ & $38.62^{\mathrm{a}}$ & $0^{\mathrm{b}}$ & $0^{\mathrm{d}}$ & $15.49^{\mathrm{cd}}$ \\
$\mathrm{CL}$ & $0.0^{\mathrm{d}}$ & $5.11^{\mathrm{c}}$ & $133.98^{\mathrm{a}}$ & $0^{\mathrm{c}}$ & $0^{\mathrm{b}}$ & $35.05^{\mathrm{a}}$ & $195.91^{\mathrm{a}}$ & $138.1^{\mathrm{a}}$ \\
$\mathrm{CM}$ & $6.7^{\mathrm{c}}$ & $0^{\mathrm{f}}$ & $15.99^{\mathrm{d}}$ & $0^{\mathrm{c}}$ & $0^{\mathrm{b}}$ & $0^{\mathrm{b}}$ & $0^{\mathrm{d}}$ & $0^{\mathrm{d}}$ \\
$\mathrm{CV}(\%)$ & 7.1 & 7.9 & 13.5 & 3.4 & 0.8 & 13 & 2.4 & 23.8 \\
$\mathrm{LSD}_{0.05}$ & 1.0 & 0.8 & 10.5 & 0.1 & 0.1 & 1.4 & 1.8 & 17.0 \\
\hline
\end{tabular}

*Values followed by the same letter within each column are not significantly different according to the LSD test at $P=0.05$. Key: GE - Green leaf discs with embryos, BE - Brown leaf discs with embryos, GW - Green leaf discs without embryo, BW - Brown leaf discs without embryos, CL- Fresh leaves (Control), CM - Fresh media (Control).

Table 2: Hydrocarbon content $(\mu \mathrm{g} / \mathrm{g})$ during development of coffee somatic embryos

\begin{tabular}{|c|c|c|c|c|c|c|c|c|c|c|c|c|c|c|c|c|c|c|c|c|c|c|}
\hline \multirow{5}{*}{$\begin{array}{l}\text { Trea } \\
\text { t- } \\
\text { men } \\
\text { ts }\end{array}$} & \multirow{5}{*}{$\begin{array}{l}\mathrm{H} \\
\mathrm{C} \\
1\end{array}$} & \multirow{5}{*}{$\begin{array}{l}\mathrm{H} \\
\mathrm{C} \\
2\end{array}$} & \multirow{5}{*}{$\begin{array}{l}\mathrm{H} \\
\mathrm{C} \\
3\end{array}$} & \multirow{5}{*}{$\begin{array}{l}\mathrm{H} \\
\mathrm{C} \\
4\end{array}$} & \multirow{5}{*}{$\begin{array}{l}\mathrm{H} \\
\mathrm{C} \\
5\end{array}$} & \multirow{5}{*}{$\begin{array}{l}\mathrm{H} \\
\mathrm{C} \\
6\end{array}$} & \multirow{5}{*}{$\begin{array}{l}\mathrm{H} \\
\mathrm{C} \\
7\end{array}$} & \multirow{5}{*}{$\begin{array}{l}\mathrm{H} \\
\mathrm{C} \\
8\end{array}$} & \multirow{5}{*}{$\begin{array}{l}\mathrm{H} \\
\mathrm{C} \\
9\end{array}$} & \multirow{5}{*}{$\begin{array}{l}\mathrm{H} \\
\mathrm{C} \\
1 \\
0 \\
\end{array}$} & \multirow{5}{*}{$\begin{array}{c}\mathrm{H} \\
\mathrm{C} \\
11\end{array}$} & \multirow{5}{*}{$\begin{array}{l}\mathrm{H} \\
\mathrm{C} \\
1 \\
2 \\
\end{array}$} & \multirow{5}{*}{$\begin{array}{l}\mathrm{H} \\
\mathrm{C} \\
1 \\
3 \\
\end{array}$} & \multirow{5}{*}{$\begin{array}{l}\mathrm{H} \\
\mathrm{C} \\
1 \\
4 \\
\end{array}$} & \multirow{5}{*}{$\begin{array}{l}\mathrm{H} \\
\mathrm{C} \\
1 \\
5 \\
\end{array}$} & \multirow{5}{*}{$\begin{array}{l}\mathrm{H} \\
\mathrm{C} \\
1 \\
6 \\
\end{array}$} & \multirow{5}{*}{$\begin{array}{l}\mathrm{H} \\
\mathrm{C} \\
1 \\
7 \\
\end{array}$} & \multirow{5}{*}{$\begin{array}{l}\mathrm{HC} \\
18\end{array}$} & \multirow{5}{*}{$\begin{array}{l}\mathrm{H} \\
\mathrm{C} \\
1 \\
9\end{array}$} & \multirow{5}{*}{$\begin{array}{l}\mathrm{H} \\
\mathrm{C} \\
2 \\
0 \\
\end{array}$} & \multirow{5}{*}{$\begin{array}{l}\mathrm{H} \\
\mathrm{C} \\
2 \\
1 \\
\end{array}$} & \multirow{5}{*}{$\begin{array}{l}\mathrm{H} \\
\mathrm{C} \\
2 \\
2\end{array}$} \\
\hline & & & & & & & & & & & & & & & & & & & & & & \\
\hline & & & & & & & & & & & & & & & & & & & & & & \\
\hline & & & & & & & & & & & & & & & & & & & & & & \\
\hline & & & & & & & & & & & & & & & & & & & & & & \\
\hline \multirow[t]{2}{*}{ GE } & 4 & 1 & & 2 & & 2 & & & & 1 & 25 & & 1 & 3 & & 4 & 0 & & & & & \\
\hline & $\begin{array}{l}6 \\
a\end{array}$ & $0^{b}$ & $5^{a}$ & $1^{\mathrm{a}}$ & $2^{\mathrm{a}}$ & $8^{b}$ & $0^{\mathrm{b}}$ & $2^{\mathrm{a}}$ & $4^{b}$ & $3^{b}$ & $3^{a}$ & $0^{b}$ & $3^{a}$ & $8^{a}$ & $0^{c}$ & $3^{a}$ & d & $0^{b}$ & $0^{b}$ & $0^{b}$ & $0^{b}$ & $0^{c}$ \\
\hline \multirow[t]{2}{*}{$\mathrm{BE}$} & 1 & $0^{c}$ & $\Omega^{c}$ & 2 & $0^{b}$ & 1 & $0^{b}$ & $0^{b}$ & $Q^{c}$ & 3 & $O^{b}$ & $\Omega^{b}$ & $\Omega^{c}$ & 1 & $\Omega^{c}$ & $7^{c}$ & 2 & $0^{b}$ & $\Omega^{b}$ & $0^{b}$ & $a^{b}$ & $\Omega c$ \\
\hline & $2^{c}$ & & 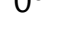 & $1^{\mathrm{a}}$ & & $1^{b}$ & & & 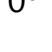 & $0^{\mathrm{a}}$ & 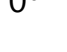 & & 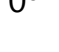 & $4^{b}$ & 0 & r & $3^{b}$ & 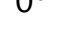 & 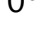 & $v$ & $v$ & $v$ \\
\hline \multirow[t]{2}{*}{ GW } & 1 & & & & & & & & & & & & & & & & & & & & & \\
\hline & $\begin{array}{l}0 \\
d\end{array}$ & $9^{a}$ & $0^{c}$ & $3^{b}$ & $0^{b}$ & $7^{d}$ & $0^{b}$ & $0^{b}$ & $0^{c}$ & $5^{c}$ & $0^{b}$ & $0^{b}$ & $0^{c}$ & $b^{c}$ & $6^{b}$ & $0^{d}$ & $9^{c}$ & $0^{\mathrm{b}}$ & $0^{b}$ & $4^{a}$ & $0^{\mathrm{b}}$ & $4^{b}$ \\
\hline \multirow[t]{2}{*}{ BW } & 2 & & & & & & & & & & & & & & & & & & & & & \\
\hline & $\begin{array}{l}1 \\
b\end{array}$ & $0^{c}$ & $0^{c}$ & $9^{c}$ & $0^{b}$ & $7^{d}$ & $\begin{array}{c}2 \\
1^{\mathrm{a}}\end{array}$ & $0^{b}$ & $9^{a}$ & $5^{c}$ & $0^{b}$ & $8^{a}$ & $0^{c}$ & $\begin{array}{c}1 \\
0^{b}\end{array}$ & $9^{a}$ & $0^{d}$ & $9^{c}$ & $\begin{array}{c}2 b \\
a\end{array}$ & $0^{b}$ & $0^{\mathrm{b}}$ & $\begin{array}{c}1 \\
2^{\mathrm{a}}\end{array}$ & $5^{a}$ \\
\hline \multirow[t]{2}{*}{$\mathrm{CL}$} & 0 & $\Omega c$ & $\Omega_{c}^{c}$ & $\Omega^{d}$ & $\Omega^{b}$ & 3 & $\Omega^{\mathrm{b}}$ & $\Omega^{b}$ & $\Omega^{c}$ & Od & $0^{b}$ & $\Omega_{\mathrm{b}}^{\mathrm{b}}$ & $\Omega^{c}$ & 4 & $\Omega c$ & Od & 5 & $\Omega^{b}$ & 3 & $\Omega^{b}$ & $0^{b}$ & 0 C \\
\hline & e & 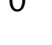 & 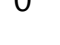 & 0 & 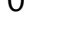 & $8^{\mathrm{a}}$ & 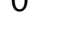 & 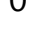 & 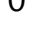 & 0 & 0 & 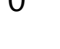 & 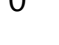 & $6^{a}$ & 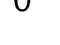 & v & $6^{a}$ & $v$ & $8^{a}$ & 0 & 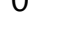 & $v$ \\
\hline CM & $\begin{array}{l}0 \\
\mathrm{e}\end{array}$ & $0^{c}$ & $\begin{array}{l}2 \\
b\end{array}$ & $0^{d}$ & $0^{b}$ & $4^{e}$ & $0^{b}$ & $0^{b}$ & $0^{c}$ & $0^{d}$ & $0^{b}$ & $0^{b}$ & $\begin{array}{r}1 \\
2^{b}\end{array}$ & $0^{c}$ & $0^{c}$ & $9^{b}$ & $\begin{array}{l}0 \\
d\end{array}$ & $0^{\mathrm{b}}$ & $0^{b}$ & $0^{\mathrm{b}}$ & $0^{\mathrm{b}}$ & $0^{c}$ \\
\hline CV ( & 5. & 1. & 2. & 2 & 2 & 8. & 4. & 3. & 1. & 1 & 28 & 9. & 6. & 8 & 4. & 2. & 4. & 32 & 0. & 5. & 2 & 6. \\
\hline$\%$ & 6 & 5 & 4 & 1 & 8 & 4 & 9 & 7 & 8 & 2 & 3.0 & 7 & 0 & 0 & 9 & 3 & 8 & 3.2 & 4 & 3 & 8 & 6 \\
\hline LSD & 1. & 0. & 0. & 4. & 0. & 2. & 0. & 0. & 0. & 1. & & 0. & 0. & 9. & 0. & 0. & 1. & ? & 0. & 0. & 1. & 0. \\
\hline 0.05 & 5 & 2 & 0 & 0 & 2 & 4 & 3 & 0 & 1 & 9 & 2.0 & 2 & 5 & 5 & 2 & 4 & 4 & 0.2 & 0 & 1 & 0 & 2 \\
\hline
\end{tabular}

*Values followed by the same letter within each column are not significantly different according to the LSD test at $P=0.05$. Key: GE - Green leaf discs with embryos, BE - Brown leaf discs with embryos, GW - Green leaf discs without embryo, BW - Brown leaf discs without embryos, CL - Fresh leaves (Control), CM - Fresh media (Control). Alkanes: HC1-[(hexadecyloxy)methyl]-Oxirane, HC2-hexadecyl-Oxirane, HC3-1,1,3,3-tetraethyl-2,1,3Oxadisilacyclopentane, HC4-n-Octylidencyclohexane, HC5-2-Trifluoroacetoxydodecane, HC6-Dodecane, HC71-iodo-Tridecane, HC8-2-Cyclopropyl carbonyloxytetradecane, HC9-1,1-bis(dodecyloxy)-Hexadecane, HC10(8)Heptadecane, HC11-Cis 7,8 epoxy-2-methyl octadecane, HC12-6-methyl-Octadecane, HC13-1- sulphonyl chloride Octadecane, HC14-2-methyltetracosane, HC15-Hexatriacontane, HC16-11,20-didecyl-Triacontane, HC17-3,5,24-trimethyl-Tetracontane. Alkenes: HC18-(Z)-3-Tetradecene, HC19-8-Heptadecene, HC20-1-chloro7-Heptadecene, HC21-(E)-9-Octadecene, HC22-1-Docosene 
Table 3: Aldehyde content $(\mu \mathrm{g} / \mathrm{g})$ during development of coffee somatic embryos

\begin{tabular}{|c|c|c|c|c|c|c|}
\hline Treatments & $\begin{array}{l}\text { 3,7-dimethyl-7- } \\
\text { Octenal, }\end{array}$ & $\begin{array}{l}\text { 2- } \\
\text { Undecenal }\end{array}$ & Dodecanal & $\begin{array}{l}\text { (E)-2- } \\
\text { Tridecenal, }\end{array}$ & Pentadecanal & $\begin{array}{l}\text { (Z)-7- } \\
\text { Hexadecenal, }\end{array}$ \\
\hline GE & $7.4^{\mathrm{a}}$ & $51.70^{a}$ & $2.22^{\mathrm{a}}$ & $0^{c}$ & $0^{c}$ & $70.19^{a}$ \\
\hline $\mathrm{BE}$ & $5.71^{b}$ & $8.87^{b}$ & $0.23^{b}$ & $0^{c}$ & $0^{c}$ & $30.86^{b}$ \\
\hline GW & $0^{c}$ & $0^{c}$ & $0^{c}$ & $3.93^{b}$ & $21.47^{a}$ & $0^{d}$ \\
\hline BW & $0^{c}$ & $0^{c}$ & $0^{c}$ & $4.83^{\mathrm{a}}$ & $17.34^{\mathrm{b}}$ & $0^{d}$ \\
\hline $\mathrm{CL}$ & $0^{c}$ & $0^{c}$ & $0^{c}$ & $0^{c}$ & $0^{c}$ & $25.74^{c}$ \\
\hline CM & $0^{c}$ & $9.72^{b}$ & $0^{c}$ & $0^{c}$ & $0^{c}$ & $0^{d}$ \\
\hline CV (\%) & 20.3 & 6.0 & 14.9 & 6.8 & 7.2 & 3.3 \\
\hline $\mathrm{LSD}_{0.05}$ & 0.8 & 1.3 & 0.1 & 0.2 & 0.8 & 1.3 \\
\hline
\end{tabular}

*Values followed by the same letter within each column are not significantly different according to the LSD test at $P=0.05$.

Key: GE - Green leaf discs with embryos, BE - Brown leaf discs with embryos, GW - Green leaf discs without embryo, BW - Brown leaf discs without embryos, CL- Fresh leaves (Control), CM - Fresh media (Control).

Table 4: Alcohol content $(\mu \mathrm{g} / \mathrm{g})$ during development of coffee somatic embryos

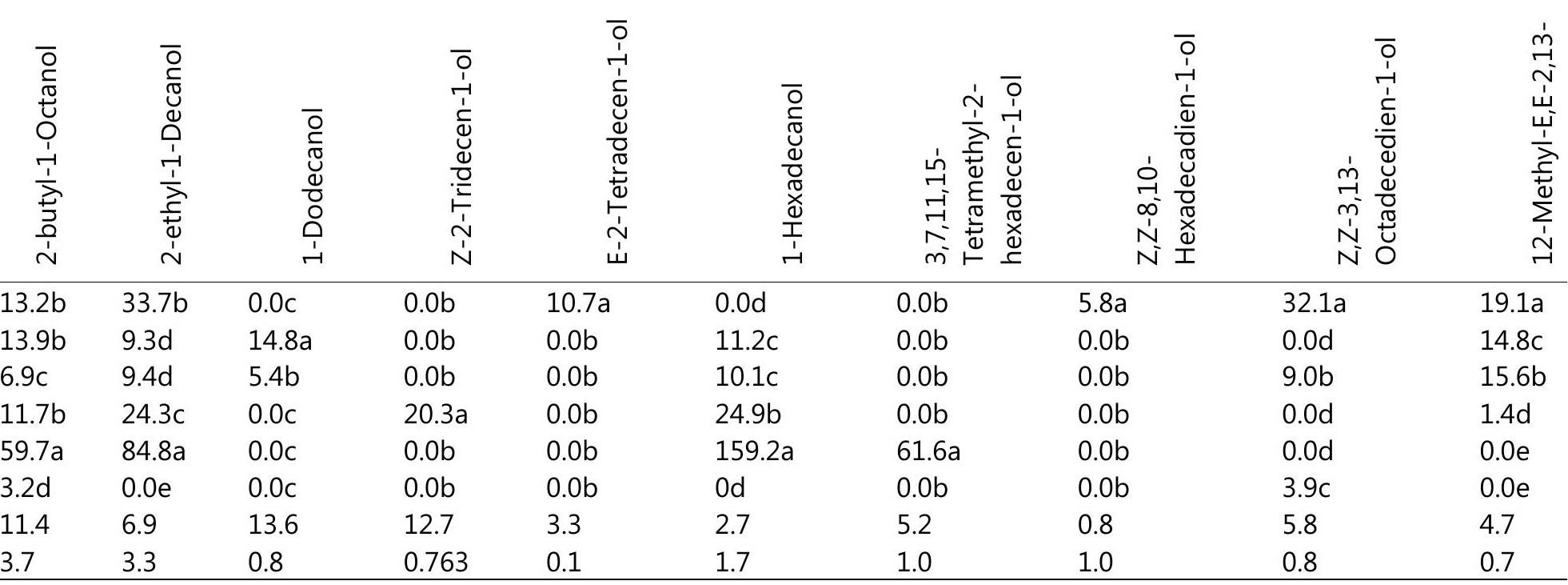

*Values followed by the same letter within each column are not significantly different according to the LSD test at $P=0.05$.

Key: GE - Green leaf discs with embryos, BE - Brown leaf discs with embryos, GW - Green leaf discs without embryo, BW - Brown leaf discs without embryos, CL - Fresh leaves (Control), CM - Fresh media (Control) 


\subsubsection{Aldehydes}

Several aldehydes were identified and quantified (Table 3) and significant $(P<0.05)$ differences were observed among them. Green cultures with embryos had the highest $(P<0.05) 7.42 \mu \mathrm{g} / \mathrm{g}$ 3,7-dimethyl-7-Octenal, 51.7 $\mu \mathrm{g} / \mathrm{g}$ 2-Undecenal, $2.22 \mu \mathrm{g} / \mathrm{g}$ Dodecanal, $70.19 \mu \mathrm{g} / \mathrm{g}$ (Z)-7-Hexadecenal, and $31.83 \mu \mathrm{g} / \mathrm{g}$ (Z)-9-Octadecenal. Green cultures without embryos had the highest $21.47 \mu \mathrm{g} / \mathrm{g}$ Pentadecanal, whereas brown cultures without embryos had the highest $4.83 \mu \mathrm{g} / \mathrm{g}(\mathrm{E})-2$-Tridecenal.

\subsubsection{Alcohols}

Various alcohols were detected during development of the somatic embryos (Table 4). Green cultures with embryos had the highest $10.74 \mu \mathrm{g} / \mathrm{g}$ E-E-2-Tetradecen-1-ol, followed by $5.79 \mu \mathrm{g} / \mathrm{g}$ Z, Z-8,10-Hexadecadien-1ol, $32.06 \mu \mathrm{g} / \mathrm{g} Z, Z-3,13-O c t a d e c e d i e n-1-o l$ and $19.1 \mu \mathrm{g} / \mathrm{g}$ 12-Methyl-E,E-2,13-octadecadien-1-ol. Brown cultures with embryos had the highest $14.79 \mu \mathrm{g} / \mathrm{g}$ 1-Dodecanol, whereas brown cultures without embryos had the highest $20.25 \mu \mathrm{g} / \mathrm{g}$ Z-2-Tridecen-1-ol. Fresh leaves had the highest $59.74 \mu \mathrm{g} / \mathrm{g}$ 2-butyl-1-Octanol, followed by $84.77 \mu \mathrm{g} / \mathrm{g}$ 2-ethyl-1-Decanol, $159.24 \mu \mathrm{g} / \mathrm{g}$ 1-Hexadecanol and $61.62 \mu \mathrm{g} / \mathrm{g}$ 3,7,11,15-Tetramethyl-2-hexadecen1 -ol.

\subsection{Other phytocomponents}

The other compounds detected during the development of coffee somatic embryos are shown in Table 5 . Compounds belonging to the ester group included: 2-Bromopropionic acid, pentadecyl ester. This compound was highest $(22.7 \mu \mathrm{g} / \mathrm{g})$ in green cultures with embryos. The 3-chloropropionic acid, heptadecyl ester was detected in green cultures with embryos, whereas 3-chloropropionic acid, tetradecyl ester was found in brown cultures without embryos. Disparlure, whose immediate direct precursor is an alkene, was detected in brown cultures without embryos. An organic compound 5-hydroxymethylfurural, which is formed through dehydration of sugars, and a steroid derivative ethyl iso-allocholate were detected in brown cultures with embryos.

Table 5: Concentration of other phytocomponents $(\mu \mathrm{g} / \mathrm{g})$ present during development of coffee somatic embryos

\begin{tabular}{llllllll}
\hline Treatments & Ester 1 & Ester 2 & Ester 3 & ketone & $\begin{array}{l}\text { Steroid } \\
\text { derivative }\end{array}$ & $\begin{array}{l}\text { Organic } \\
\text { compound }\end{array}$ & Disparlure \\
\hline $\mathrm{GE}$ & $22.7^{\mathrm{a}}$ & $16.0^{\mathrm{a}}$ & $0.0^{\mathrm{c}}$ & $27.2^{\mathrm{b}}$ & $0.0^{\mathrm{b}}$ & $0.0^{\mathrm{b}}$ & $0.0^{\mathrm{b}}$ \\
$\mathrm{BE}$ & $12.0^{\mathrm{b}}$ & $0.0^{\mathrm{b}}$ & $0.0^{\mathrm{c}}$ & $34.8^{\mathrm{a}}$ & $23.6^{\mathrm{a}}$ & $12.1^{\mathrm{a}}$ & $0.0^{\mathrm{b}}$ \\
$\mathrm{GW}$ & $0.0^{\mathrm{c}}$ & $0.0^{\mathrm{b}}$ & $0.0^{\mathrm{c}}$ & $1.5^{\mathrm{d}}$ & $0.0^{\mathrm{b}}$ & $0.0^{\mathrm{b}}$ & $0.0^{\mathrm{b}}$ \\
$\mathrm{BW}$ & $0.0^{\mathrm{c}}$ & $0.0^{\mathrm{b}}$ & $5.5^{\mathrm{b}}$ & $9.4^{\mathrm{c}}$ & $0.0^{\mathrm{b}}$ & $0.0^{\mathrm{b}}$ & $17.0^{\mathrm{a}}$ \\
$\mathrm{CL}$ & $0.0^{\mathrm{c}}$ & $0.0^{\mathrm{b}}$ & $0.0^{\mathrm{c}}$ & $0.0^{\mathrm{d}}$ & $0.0^{\mathrm{b}}$ & $0.0^{\mathrm{b}}$ & $0.0^{\mathrm{b}}$ \\
$\mathrm{CM}$ & $0.0^{\mathrm{c}}$ & $0.0^{\mathrm{b}}$ & $7.9^{\mathrm{a}}$ & $0.0^{\mathrm{d}}$ & $0.0^{\mathrm{b}}$ & $0.0^{\mathrm{b}}$ & $0.0^{\mathrm{b}}$ \\
$\mathrm{CV}(\%)$ & 3 & 3.3 & $5 .^{6}$ & 21.7 & 6.2 & 23.7 & 0.4 \\
$\mathrm{LSD}_{0.05}$ & 0.3 & 0.1 & 0.2 & 4.7 & 0.4 & 0.8 & 0.02 \\
\hline
\end{tabular}

*Values followed by the same letter within a column are not significantly different as per the LSD test at $P=$ 0.05 .

Key: GE - Green leaf discs with embryos, BE - Brown leaf discs with embryos, GW - Green leaf discs without embryo, BW - Brown leaf discs without embryos, CL- Fresh leaves (Control), CM - Fresh media (Control). Ester 1-2-Bromopropionic acid, pentadecyl ester, Ester 2-3-Chloropropionic acid, heptadecyl ester, Ester 3-3Chloropropionic acid, tetradecyl ester, Ketone- 9,9-Dimethoxybicyclo[3.3.1]nona-2,4-dione, Steroid derivative Ethyl iso-allocholate, Organic compound -5-Hydroxymethylfurfural

\subsection{Evaluation of amino acids}

Out of the 20 common amino acids, 13 were identified in leaf discs and embryos of coffee. There were significant $(P<0.05)$ differences in the endogenous amino acid identified in leaf disc and somatic embryo samples (Table 6). The highest were $1.89 \mu \mathrm{g} / \mathrm{g}$ alanine and $1.55 \mu \mathrm{g} / \mathrm{g}$ arginine in green leaf discs with embryos, although not 
significantly different from those in brown leaf discs with embryos, but these contents were significantly $(P<0.05)$ different from the other treatments. With aspartic acid, glutamic acid, phenylalanine, serine and threonine, there were no significant $(P>0.05)$ differences among green leaf discs with embryos and brown leaf discs with and without embryos.

Brown leaf discs with embryos had significantly $(P<0.05)$ the highest $2.52 \mu \mathrm{g} / \mathrm{g}$ glycine, followed by $1.36 \mu \mathrm{g} / \mathrm{g}$ isoleucine, $0.93 \mu \mathrm{g} / \mathrm{g}$ leucine, $2.01 \mu \mathrm{g} / \mathrm{g}$ methionine and $0.93 \mu \mathrm{g} / \mathrm{g}$ valine. Lysine was highest $(P<0.05)$ in both brown leaf discs with $(1.82 \mu \mathrm{g} / \mathrm{g})$ and without $(1.40 \mu \mathrm{g} / \mathrm{g})$ embryos. Embryos developed from brown leaf discs had significantly $(P<0.05)$ the highest content of all the 13 amino acids identified.

\section{DISCUSSION}

\subsection{Phytocomponents}

Both saturated fatty acids (SFA) and unsaturated fatty acids (UFA) accounted for the highest quantities of phytocomponents detected in green and brown leaf disc cultures with and without embryos. Fatty acids are used in formation of new membranes during rapid growth of embryos and are assembled into triacylglycerols that are specifically synthesized during embryo development and used as energy sources during germination (Wurtele and Nikolau, 1992). 
Table 6: Identification and quantification of amino acids $(\mu \mathrm{g} / \mathrm{g})$ present during development of coffee somatic embryos in vitro.

\begin{tabular}{|c|c|c|c|c|c|c|c|c|c|c|c|c|c|}
\hline & Ala & Arg & Asp & Glu & Gly & Ile & leu & Lys & Met & Phe & Ser & Thr & Val \\
\hline \multicolumn{14}{|c|}{ Leaves } \\
\hline GE & $1.89^{a}$ & $1.45^{\mathrm{a}}$ & $2.11^{a}$ & $0.53^{a}$ & $1.24^{b}$ & $0.88^{b}$ & $0.74^{b}$ & $1.30^{\mathrm{b}}$ & $1.11^{b}$ & $0.78^{a}$ & $0.63^{a}$ & $0.30^{\mathrm{ab}}$ & $0.32^{b}$ \\
\hline$B E$ & $1.65^{\mathrm{a}}$ & $1.55^{\mathrm{a}}$ & $1.56^{\mathrm{ab}}$ & $0.636^{a}$ & $2.52^{\mathrm{a}}$ & $1.36^{\mathrm{a}}$ & $0.93^{\mathrm{a}}$ & $1.82^{\mathrm{a}}$ & $2.01^{a}$ & $0.80^{\mathrm{a}}$ & $0.64^{a}$ & $0.37^{a}$ & $0.93^{\mathrm{a}}$ \\
\hline GW & $0.65^{c}$ & $0.54^{b}$ & $1.07^{b c}$ & $0.24^{b}$ & $0.74^{c}$ & $0.33^{c}$ & $0.24^{c}$ & $0.39^{c}$ & $0.70^{c}$ & $0.34^{b}$ & $0.39^{b}$ & $0.22^{\mathrm{bc}}$ & $0.35^{b}$ \\
\hline BW & $1.13^{b}$ & $0.8^{\mathrm{b}}$ & $2.06^{a}$ & $0.73^{a}$ & $1.43^{b}$ & $0.77^{b}$ & $0.35^{c}$ & $1.40^{\mathrm{ab}}$ & $0.65^{c}$ & $0.82^{\mathrm{a}}$ & $0.54^{a}$ & $0.35^{\mathrm{a}}$ & $0.37^{b}$ \\
\hline$C L$ & $0.29^{d}$ & $0.18^{c}$ & $0.53^{c}$ & $0.26^{b}$ & $0.51^{c}$ & $0.13^{c}$ & $0.22^{c}$ & $0.36^{c}$ & $0.52^{c}$ & $0.24^{b}$ & $0.16^{c}$ & $0.16^{c}$ & $0.06^{c}$ \\
\hline $\begin{array}{l}\text { CV } \\
\text { (\%) }\end{array}$ & 16.8 & 21.0 & 21.4 & 25.5 & 18.0 & 19.1 & 19.5 & 26.8 & 20.4 & 15.6 & 11.3 & 17.4 & 29.8 \\
\hline $\mathrm{LSD}_{0.05}$ & 0.3 & 0.3 & 0.6 & 0.2 & 0.4 & 0.2 & 0.2 & 0.5 & 0.4 & 0.2 & 0.1 & 0.1 & 0.2 \\
\hline \multicolumn{14}{|c|}{ Embryos } \\
\hline GE & $1.37^{b}$ & $0.96^{b}$ & $2^{b}$ & $0.7^{9 b}$ & $1.3^{b}$ & $0.78^{b}$ & $0.56^{b}$ & $1.28^{\mathrm{b}}$ & $0.78^{b}$ & $0.88^{b}$ & $0.73^{b}$ & $0.30^{b}$ & $0.37^{b}$ \\
\hline$B E$ & $4.41^{\mathrm{a}}$ & $3.18^{a}$ & $4.4^{a}$ & $2.2^{\mathrm{a}}$ & $3.14^{\mathrm{a}}$ & $2.68^{a}$ & $2.58^{\mathrm{a}}$ & $4.29^{\mathrm{a}}$ & $2.13^{a}$ & $3.73^{\mathrm{a}}$ & $1.63^{a}$ & $0.68^{a}$ & $1.94^{\mathrm{a}}$ \\
\hline GW & $0.00^{c}$ & $0.00^{c}$ & $0.00^{c}$ & $0.00^{c}$ & $0.00^{c}$ & $0.00^{c}$ & $0.00^{c}$ & $0.00^{c}$ & $0.00^{c}$ & $0.00^{c}$ & $0.00^{c}$ & $0.00^{c}$ & $0.00^{c}$ \\
\hline BW & $0.00^{c}$ & $0.00^{c}$ & $0.00^{c}$ & $0.00^{c}$ & $0.00^{c}$ & $0.00^{c}$ & $0.00^{c}$ & $0.00^{c}$ & $0.00^{c}$ & $0.00^{c}$ & $0.00^{c}$ & $0.00^{c}$ & $0.00^{c}$ \\
\hline$C L$ & $0.00^{c}$ & $0.00^{c}$ & $0.00^{c}$ & $0.00^{c}$ & $0.00^{c}$ & $0.00^{c}$ & $0.00^{c}$ & $0.00^{c}$ & $0.00^{c}$ & $0.00^{c}$ & $0.00^{c}$ & $0.00^{c}$ & $0.00^{c}$ \\
\hline $\begin{array}{l}\text { CV } \\
(\%)\end{array}$ & 13.6 & 16.1 & 2.9 & 11.1 & 7.4 & 13.9 & 20.4 & 29.8 & 3.9 & 7.3 & 14.1 & 28.1 & 11.7 \\
\hline $\mathrm{LSD}_{0.05}$ & 0.3 & 0.2 & 0.1 & 0.1 & 0.1 & 0.2 & 0.2 & 0.6 & 0.04 & 0.1 & 0.1 & 0.1 & 0.1 \\
\hline
\end{tabular}

*Values followed by the same letter within each column are not significantly different according to the LSD test at $P=0.05$

Key: GE - Green leaf discs with embryos, BE - Brown leaf discs with embryos, GW - Green leaf discs without embryo, BW - Brown leaf discs without embryos, CL- Fresh leaves (Control), CM - Fresh media (Control).

Amino acids: Ala- Alanine, Arg- Arginine, Asp- Aspartic acid, Glu- Glutamic acid, Gly- Glycine, Ile- Isoleucine, Lys- Lysine, Met- Methionine, Phe- Phenylalanine, Ser- Serine, Thr- Threonine, Val- Valine 
Storage lipids accumulate primarily during the maturation phase of embryo development. Fatty acids C16:1, C18:1, Trans C18:1, C16:0, C17:0 and C18:0 were obtained in embryogenic cultures. Similarly, Aly et al., (2008) reported that somatic embryos of jojoba contained $C 16: 0, C 18: 0,18: 1,18: 2$ and 18:3, indicating that these fatty acids stimulated somatic embryogenesis.

Oxygen esters of fatty alcohols and fatty acids are main components of biological systems. These components are found on the surface of plants and animals and protect against desiccation, wetting, and pathogen attack. Negi et al., (2005) reported that unsaturated fatty acids are essential in producing an active compound that acts as an auxin-like plant growth promoter when linked to an aromatic molecular base like napthtophenone, indicating the important role that the unsaturated fatty acids play in biochemical mechanisms in plants. This may be the reason why unsaturated fatty acids were detected during development of coffee somatic embryos. Higher quantities of fatty acids may have resulted from cell membrane degradation. Aly et al., (2008) reported that the presence of fatty acids in leaf-derived jojoba somatic embryos and leaves demonstrates that synthesis of fatty acids is developmentally regulated and that in vitro induction of linoleic acid (C18:2) and linolenic acid (C18:3) fatty acids had taken place. Carrier et al., (1997) reported that, most abundant fatty acid in white spruce somatic embryos was linoleic acid (18:2) followed by oleic acid (18:1) and linolenic acid (C18:3), meaning somatic embryos contained greater levels of UFA.

Alkanes are widely distributed in the plant kingdom although their physiological role is not well understood. Cunha and Fernandes-Ferreira (2001) suggested that the $\mathrm{n}$-alkane variation can be in time, where there is a decline during cellular multiplication and growth; and in space, where carbon mobilization from embryogenic callus is related to somatic embryo differentiation. Lamarque et al., (1998) indicated that the n-alkanes in seed oil and internal hydrocarbons may play a role in maintaining inner cell structure and act as energy storage components. Cunha and Fernandes-Ferreira (2001) postulated the role for short-chain n-alkanes, as translocable reduced carbon reserves in initial process of embryo germination from somatic tissues.

Fatty acids and/or their derivatives seem to be closely related to the direct precursor for hydrocarbons produced in plants (Kaneda, 1969). Plant species, age and tissue type determine the nature of fatty acids found, and accumulation of these fatty acids is due to their important role as photosynthesis intermediaries (Ahmad et al., 2014). In the present study, majority of the aldehydes detected probably arose from degradation of polyunsaturated fatty acids either by autoxidation or action of enzymes such as lipoxygenases (Takahashi et al., 2002). Plant volatiles are derived by oxidative cleavage and decarboxylation of fatty acids, resulting in production of short-chain volatiles with aldehyde and ketone moieties. These compounds originate from $\mathrm{C} 18$ unsaturated fatty acids (linoleic or linolenic), which enter the "lipoxygenase pathway" ((Fu et al., 2015). Lipid peroxidation occurs in response to oxidative stress, and diverse aldehydes are formed when lipid hydroperoxides break down in biological systems. Some of these aldehydes are highly reactive and may be considered as second toxic messengers that disseminate and augment initial free radical events (Eldin and Ibrahim, 2015).

Both green and brown embryogenic cultures generally released more and higher quantities of volatile compounds as compared to non-embryogenic cultures. As postulated by Alonzo et al., (2001) embryogenic competence appeared to be related to biochemical activity, including synthesis of volatile compounds. Embryogenic competence appeared to be related to the synthesis of phytocomponents. However, uncertainty remains whether the differences observed were due to differential biochemical maturation of the not fully organized cellular tissues.

\subsection{Amino acids}

Amino acids are considered important regulators of morphogenesis in several plant species. In the present study, endogenous amino acids varied during somatic embryogenesis. Embryos formed in brown leaf discs had higher amino acids than those formed in green leaf discs. In descending order, alanine, aspartic acid, lysine, phenylalanine, arginine and glycine were the major amino acids in the embryos and accounted for $64.4 \%$ and $62.6 \%$ for the green and brown leaf discs, respectively. The high amino acid content may be due to high synthesis 
required for cell differentiation leading to plant regeneration. When compared with the other amino acids, alanine composition was highest in embryos formed from brown leaf discs. Saranga et al., (1992) also reported highest alanine content in celery somatic embryos. Salonen (1980) reported that alanine has been found to stimulate cell growth greatly in several other plant species.

Sen et al (2002) reported that during embryogenesis of Vigna mungo (L.), amino acids such as phenylalanine, lysine, arginine, aspartic acid and serine were present in higher levels compared to the other amino acids in regenerated plantlets. Accumulation of amino acids has been reported during the induction phase, which has been suggested to be due to enhanced biosynthesis rather than reduced catabolism (Sen et al., 2002). Endogenous glutamine and arginine were associated with early development of white pine (Pinus strobes) zygotic embryos (Feirer, 1995), indicating their importance in tissue proliferation and growth. Arginine is an important precursor of polyamine biosynthesis via the arginine decarboxylase pathway (Minocha et al., 2004). The high lysine found in the present study may have encouraged plantlet regeneration via embryogenesis.

Aspartic acid was highest in embryos formed in green and brown leaf discs and this accumulation as storage protein could be due to higher proportion of nitrogen in its molecule (Payne, 1986). The acid-hydrolysis used for the determination of the amino acid composition of coffee embryos did not allow differentiation between asparagine and glutamine amino acids and their acidic forms. This challenge has also been reported for coffee seeds (Shimizu and Mazzafera, 2000) and celery somatic embryos (Saranga et al., 1992). In the present study, high levels of glycine were present in embryos particularly those formed in brown leaf discs. This result was attributed to the fact that this amino acid is an essential precursor for the synthesis of proteins and nucleic acids. Ornithine was not detected in this study, because it may have been converted into arginine as in the case of Acca sellowiana (Cangahuala-Inocente et al., 2014).

\section{CONCLUSION AND RECOMMENDATIONS}

Several phyto-components and amino acids were identified during development of coffee somatic embryos. Fatty acids, alcohols, aldehydes and hydrocarbons were identified in in vitro cultures of coffee. Embryogenic cultures generally released more and higher quantities of phyto-components as compared to non-embryogenic cultures. Endogenous amino acid content was highest in brown embryogenic cultures. Embryogenic competence in coffee appeared to be related to the synthesis of phyto-components and amino acids. Further studies on the phyto-components can be useful in biochemical, genetic and breeding research in coffee.

\section{ACKNOWLEDGEMENTS}

This study was co-financed by the Coffee Research Institute and the National Council of Science, Technology and Innovation grant reference number NACOSTI/RCD/ST\&I $5^{\text {th }}$ Call PhD/026. Thanks to the technical staff of the Crop Physiology and Chemistry quality Units for their assistance. This paper is published with the permission of the Institute Director of the CRI on behalf of the Director General, Kenya Agricultural and Livestock Research Organization.

\section{REFERENCES}

1. Ahmad, R., Baharum, S. N., Bunawan, H., Minki Lee, M., Noor, N. M., Rohani, E., Ilias, N., and Zin, N.M. 2014. Volatile profiling of aromatic traditional medicinal plant, Polygonum minus in different tissues and its biological activities. Molecules 19: 19220-19242.

2. Alonzo, G., Saiano, F., Tusa, N., and Del Bosco, S.F. 2001. Analysis of volatile compounds released from embryogenic cultures and somatic embryos of sweet oranges by head space SPME. Plant Cell, Tissue and Organ Culture 66: 31-34.

3. Aly, M. A. M., Amer, E. A., Al-Zayadneh, W. A., and Edin A. E. N. 2008. Growth regulators influence the fatty acid profiles of in vitro induced jojoba somatic embryos. Plant Cell Tissue and Organ Culture 93: 107-114. 
4. Cangahuala-Inocente, G.C., Silveira, V., Caprestano, C. Floh, A I. S. and Guerra, M. P. 2014. Dynamics of physiological and biochemical changes during somatic embryogenesis of Acca sellowiana. In Vitro Cell. Dev. Biol. - Plant. 50: 166-175

5. Cunha, A., C. and Fernandes-Ferreira, M. 2001. Ontogenic variations in $n$-alkanes during somatic embryogenesis of flax (Linum usitatissimum L.). Plant Sci., 160: 1137-1143.

6. Dong, W., Tan L., Zhao, J., Hu R., and Lu, M. 2015. Characterization of fatty acid, amino acid and volatile compound compositions and bioactive components of seven coffee Coffea robusta cultivars grown in Hainan Province, China. Molecules 20: 16687-16708.

7. El Hadi, M. A., Zhang, F., Wu, F., Zhou C., and Jun Tao, J. 2013. Advances in fruit aroma volatile research: A review. Molecules 18: 8200-8229.

8. Eldin, A. F. M. Z., and Ibrahim, H. A. 2015. Some biochemical changes and activities of antioxidant enzymes in developing date palm somatic and zygotic embryos in vitro. Annals of Agricultural Science 601: 121-130.

9. Feirer, R. P. 1995. Biochemistry of conifer embryo development: Amino acids, polyamines and storage proteins. In: Jain, S. M., Gupta, P. K. and Newton, R.J. (Eds.). Somatic embryogenesis in woody plants. Kluwer Academic Publishers, Dordrecht, 1: 317-336.

10. Fu, X., Zhou, Y., Zeng, L., Dong, F., Mei,,X., Liao,Y., Watanabec, N., and Yang, Z. 2017. Analytical method for metabolites involved in biosynthesis of plant volatile compounds RSC Adv. 7: 19363

11. Jaetzold, R., Schmidt, H., Hornet, Z. B., and Shisanya, C. A. 2007. Farm Management Handbook of Kenya. Natural Conditions and Farm Information. $2^{\text {nd }}$ Edition. Vol. 11/B. Central Kenya. Ministry of Agriculture/GTZ, Nairobi, Kenya

12. Kaneda, T. 1969. Hydrocarbons in spinach: Two distinctive carbon ranges of aliphatic hydrocarbons. Phytochemistry, 8: 2039-2044.

13. Karimi, E., Jaafar, H.Z.E., Ghasemzadeh, A. and Ebrahimi, M. 2015. Fatty acid composition, antioxidant and antibacterial properties of the microwave aqueous extract of three varieties of Labisia pumila Benth. Biological Research 48:9.

14. Koorneef, M., and Karssen, C. M. 1994. Seed dormancy and germination, p. 313-334. In: E.M. Meyerowitz and C.R. Sommerville (Eds.). Arabidopsis, Cold Spring Harbor Laboratory Press, Cold Spring Harbor.

15. Lulsdorf, M. M., Tautorus, T. E., Kikcio, S. I., and Dunstan, D. I. 1992. Growth parameter of somatic embryogenic suspension culture of interior spruce Picea glauca-engelmannii complex and black spruce (Picea mariana Mill.). Plant Sci. 82: 27-234.

16. Minocha, R., Minocha, S.C., and Long, S. 2004. Polyamines and their biosynthetic enzymes during somatic embryo development in red spruce (Picea rubens Sarg.). In Vitro Cellular and Developmental Biology-Plant, 406: 572-80.

17. Navarro, B. V., Elbl, P., De Souza, A. P., Jardim, V., de Oliveira, L. F., Macedo, A. F., and Floh, E. I. S. 2017. Carbohydrate-mediated responses during zygotic and early somatic embryogenesis in the endangered conifer, Araucaria angustifolia. PLOS ONE, 127.

18. Negi, A. S., Darokar, M.P., Chattopadhyay, S. K., Garg, A., Bhattacharya, A.K., Srivastava, V., Khanuja, S. P.S. 2005. Synthesis of a novel plant growth promoter from gallic acid. Bioorg Med Chem Lett 15: 1243-1247.

19. Payne, P.I. 1986. Endosperm proteins. In: A.D. Blonstein P.J. King. (Eds.). A Genetic Approach to Plant Biochemistry. pp 205-231 New York, USA: Springer-Verlag

20. Salonen, M. L. 1980. Glutamate- and aspartate-derived amino acids as nitrogen sources for the callus of Atropa belladonna L. Annales Botanici Fennici 17: 357-378

21. Saranga, Y., Rhodes, D. and Janick, J. 1992. Changes in amino acid composition associated with tolerance to partial desiccation of celery somatic embryos. J. Amer. Soc. Hort. Sci. 1172: 337-341.

22. Sen, J., Kalia, S., and Guha-Mukherjee, S. 2002. Level of endogenous free amino acids during various stages of culture of Vigna mungo L. Hepper-somatics embryogenesis, organogenesis and plant regeneration. Current Science 824: 429-433.

23. Shimizu, M. M., and Mazzafera, P. 2000. Compositional changes of proteins and amino acids in germinating coffee seeds. Brazilian Archives of Biology and Techn., 433: 259-265.

24. Takahashi, H., Sumitani, H., Inada, Y. and Mori, D. 2002. Identification of volatile compounds of Kombu (Laminaria spp.) and their odour description. Nippon Kagaku Kaishi 49 4: 228-237. 
25. Wurtele, E. S., and Nikolau, B. J. 1992. Differential accumulation of biotin enzymes during carrot somatic embryogenesis. Plant Physiol. 99: 1699-1703.

26. Yadegari, R. and Goldberg, R. 1997. Embryogenesis in dicotyledonous plants, p. 3-52. In: B. A. Larkins and I. K. Vasil (Eds.). Cellular and Molecular Biology of Plant Seed Development, Kluwer Academic Publishers, Dordrecht.

\section{Conflicts of Interest}

The authors declare that there is no conflict of interest regarding the publication of this article.

\section{Authors' Biographies with Photos}

Dr. Rose N. Mayoli was born in 1978 in Machakos-Kenya, and received both her B.Sc. in Horticulture in 2003 and M.Sc. in 2008 from Egerton University, Kenya and Ph.D. in Plant Biotechnology in 2018 from Chuka University, Kenya. Dr. Mayoli's work experience has included: July 2003-August 2003 Quality Controller, Equator Flowers Kenya Limited, August 2003-August 2004 Assistant Production Manager, Carzan Flowers Kenya Limited; January 2009-July 2009 Senior Quality Control Supervisor, Primarosa Flowers Kenya Limited; September 2009-date, Research Officer and Head of Plant Physiology Unit, Coffee Research Institute, Kenya Agricultural and Livestock Research Organization. Dr. Mayoli's research interests concern horticulture, floriculture, beverage crops, plant growth regulators, plant tissue culture, plant biotechnology, molecular biology, and plant physiology.

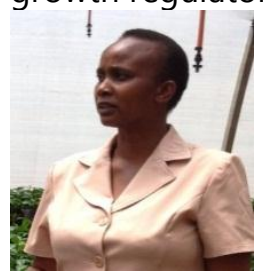

Prof. Dorcas K. Isutsa was born in 1966 in Kakamega and has earned the following: 2004-2005 Academic \& Research Fellow Certificate, University of Reading, UK, 26 Apr-2 July 2004 Plant Biotechnology, Biosafety \& Biotechnology Certificate, Wageningen International Agricultural Centre, Netherlands; 1994-1998 Ph.D. in Horticulture, 1991-1993 M.Sc. in Pomology both from Cornell University, USA, and 1987-1990 a B.Sc. in Horticulture, Egerton University, Kenya. Prof. Isutsa has held the following administrative positions: from $11^{\text {th }}$ Sept. 2013-date, Deputy Vice-Chancellor (Academic, Research \& Student Affairs); Jan-Aug. 2013, Ag. Deputy Vice-Chancellor (Academic Affairs) of Chuka University; Mar. 2011-Jan. 2013, Deputy Principal, Chuka University College. Prof. Isutsa has worked in professional positions as follows: $15^{\text {th }}$ Sep. 2013-date, Full Professor; October 2003-Sep. 2013, Associate Professor; June 1999-Sep. 2003, Senior Lecturer; Feb. 1997-May 1999, Lecturer; June 1993-1997, Assistant Lecturer; Oct. 1990-May 1993, Teaching Assistant, all at Egerton University, Njoro; 19941998, Research Assistant, and parts of 1991-1998, Teaching Assistant, Cornell University, USA. Prof. Isutsa's research interests include fruit sciences, plant nursery and orchard management, plant biotechnology, and horticulture.

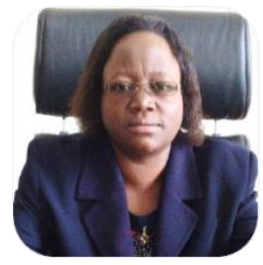

Prof. Aggrey B. Nyende was born in 1966 in Kakamega, Kenya and pursued University education as follows: 1986-1989 B.Sc. (Agriculture); 1989-1991 M.Sc. (Plant Breeding and Genetics) both from University of Nairobi (Kenya); 2000-2003 Doctorate (Agricultural Science) Kiel University (Germany); Prof. Aggrey B. Nyende's worked as follows: 1985-1986, Civil servant: Cartography Department. Ministry of Finance and Economy; 1990-1991, Research Assistant: Pigeonpea Improvement Project-Crop Science Department, University of Nairobi; 1993, 
Energy Conservation Officer: Eukawa Technical Services, Kiambu; 1994-1999, Self-employed: Agricultural consultation services to flower and horticultural farmers in Kenya; 1994-1999 (2005), Lecturer (Part-time): Horticulture/Botany departments, Jomo Kenyatta University for Agriculture and Technology (JKUAT); 2000-2003, Research Fellow: Institute for Crops and Grassland Sciences, Federal Agricultural Research Centre, Braunschweig, Germany; 2005, Netherlands Scholarship Fellow: Plant breeding and Biotechnology training; 2006 to 2008, Lecturer: Horticulture Department-JKUAT; 2008 to 2012, Senior Lecturer, Horticulture Department; 2013-date, Associate Professor, JKUAT; 2008-2011, In-Country Co-supervisor: University of Kwazulu-Natal; 2008-date, Director, Institute for Biotechnology Research (JKUAT) for biotechnology and tissue culture research and development, training in biotechnology at postgraduate level, and supporting structure for biotechnology research innovations and products. Prof. Nyende's research interests are in molecular biology, plant breeding and tissue culture.

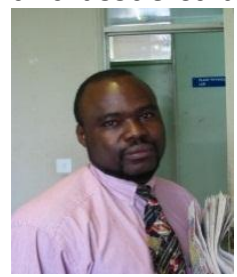

Dr. Cecilia Mbithe Mweu was born in 1975 in Machakos, Kenya. Dr. Mweu's academic background includes 20082012 PhD. (Biotechnology), JKUAT, Kenya; 2005-2006 Development Oriented Plant Biotechnology and Biosafety, Germany; 2002-2004 M.Sc. (Natural Products and Biotechnology), MAICH, Greece; 2001-2002 Post graduate Diploma (Natural Products and Biotechnology), MAICH, Greece; 1996-2000: B.Sc. (Botany and Zoology), University of Nairobi, Kenya. From 2004-2007, she worked as a Research Scientist, Department of Molecular Genetics, National Museums of Kenya. Presently, Dr. Mweu is a researcher/lecturer at the Institute of Biotechnology Research of Jomo Kenyatta University of Agriculture and Technology, Kenya. Dr. Mweu's research interests include molecular biology, tissue culture, phytochemistry and genetic engineering.

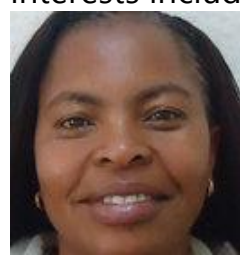

